\title{
Wage stickiness and unemployment fluctuations: an alternative approach
}

\author{
Miguel Casares • Antonio Moreno • Jesús Vázquez
}

Received: 25 September 2010 / Accepted: 29 August 2011 / Published online: 21 September 2011 (C) The Author(s) 2011. This article is published with open access at SpringerLink.com

\begin{abstract}
Erceg et al. (J Monet Econ 46:281-313, 2000) introduce sticky wages in a New-Keynesian general-equilibrium model. Alternatively, it is shown here how wage stickiness may bring unemployment fluctuations into a New-Keynesian model. Using a Bayesian econometric approach, both models are estimated with US quarterly data of the Great Moderation. Estimation results are similar in the two models and both provide a good empirical fit, with the crucial difference that our model delivers unemployment fluctuations. Thus, second-moment statistics of the US rate of unemployment are replicated reasonably well in our proposed New-Keynesian model with sticky wages. Demand-side shocks play a more important role than technology innovations or cost-push shock in explaining both output and unemployment fluctuations. In the welfare analysis, the cost of cyclical fluctuations during the Great Moderation is estimated at $0.60 \%$ of steady-state consumption.
\end{abstract}

Keywords Wage rigidity $\cdot$ Price rigidity $\cdot$ Unemployment

We thank Gabriel Pérez-Quirós, two anonymous referees, and Francisco Galera for comments and suggestions. Financial support through research projects ECO2008-02641, ECO2009-11151,

SEJ2007-66592-C03-01/ECON and ECO2010-16970 from Ministerio de Ciencia e Innovación (Spain) is also acknowledged. The first author also thanks Fundación Ramón Areces (VII Concurso Investigación en Economía) for financial support.

M. Casares $(\varangle)$

Departamento de Economía, Universidad Pública de Navarra, Pamplona, Spain e-mail: mcasares@unavarra.es

\section{A. Moreno}

Departamento de Economía, Universidad de Navarra, Pamplona, Spain e-mail: antmoreno@unav.es

\section{J. Vázquez}

Departamento FAE II, Universidad del País Vasco, Bilbao, Spain

e-mail: jesus.vazquez@ehu.es 


\section{JEL Classification $\quad \mathrm{C} 32 \cdot \mathrm{E} 30$}

\section{Introduction}

The basic New-Keynesian model (Woodford, 2003; chapter 3) has been extended in recent years to incorporate the endogenous determination of unemployment fluctuations in the labor market. ${ }^{1}$ For instance, Walsh (2005) and Trigari (2009) combined search frictions of the kind introduced in the Mortensen and Pissarides (1994) framework with sticky prices à la Calvo (1983). As a result, unemployment fluctuates due to some real rigidity, i.e. the search and matching cost faced by the firm during the hiring process.

Alternatively, this paper relies on Casares $(2007,2010)$ and Galí (2011) to incorporate unemployment fluctuations to the New-Keynesian model driven by sticky wages. Wage rigidity explains why there are mismatches between labor supply (workers) and labor demand (jobs) in the fraction of non-renegotiated labor contracts. In turn, labor fluctuations are driven exclusively by changes in the level of employment which might be considered a fair simplification of reality. ${ }^{2}$ Consequently, the household's disutility of work only varies when there are changes in the number of family members employed. This difference becomes crucial when bringing the models to the data, as unemployment fluctuations can be retrieved from the data whereas the difference between total hours supplied and total hours demanded is not observable.

The model used in this paper extends that of Casares (2010) in two dimensions: (i) it incorporates price and wage indexation rules, and (ii) it adds new sources of business cycle fluctuations such as demand shocks and cost-push shocks. The difference between this model and that of Galí (2011) is that unemployment is here determined at a decentralized firm level, whereas Galí (2011) directly obtains unemployment as the difference between aggregate labor demand and a measure of aggregate labor supply. Another difference is that Galí (2011) maintains the assumption of market power of households to determine wages, whereas this paper includes an intertemporal equation to determine wages that match labor supply and labor demand. ${ }^{3}$

What are the empirical implications of having unemployment as excess supply of labor in a New-Keynesian model? We address this question by following a Bayesian econometric approach to estimate the unemployment model using US quarterly data from the Great Moderation period (1984-2008). The estimation results provide a good fit of the model to the data and suggest that the measures of price and wage stickiness

\footnotetext{
${ }^{1}$ There have also been other remarkable extensions such as the open-economy framework (Galí and Monacelli 2005), endogenous inertia from consumption habit formation, price/wage indexation rules or investment adjustment costs (Smets and Wouters 2003, 2007; Christiano et al. 2005) and the introduction of banking activities (Goodfriend and McCallum 2007; Christiano et al. 2008).

2 It is generally accepted that most variability of US total hours worked is explained by changes in the number of employed people (extensive margin) whereas the number of hours at work (intensive margin) has significantly less influence. Quoting the abstract of Cho and Cooley (1994): "Approximately one quarter of the adjustment in total hours of employment over the business cycle represents adjustments in hours, while the remainder is explained by changes in employment".

${ }^{3}$ Both models agree on taking effective employment from labor demand as usually assumed in Keynesian textbook-type models (e.g., Abel et al. 2011, chapter 11).
} 
are quantitatively high and similar. We also estimate the model derived by Erceg et al. (2000) as a natural benchmark for a comparison with a sticky-wage New-Keynesian model that displays no unemployment fluctuations (so-called Dynamic Stochastic General Equilibrium, DSGE, models). ${ }^{4}$ Throughout the paper, EHL is the acronym used to refer to the model based on the paper by Erceg et al. (2000) whereas CMV is the name of the alternative sticky-wage model (CMV comes from the initials of our last names). While the parameter estimates are rather similar across models, the estimates obtained for Calvo probabilities suggest slightly shorter price stickiness and longer wage stickiness in the CMV model compared to the EHL model. Moreover, the estimate of the price inflation inertial component is lower in the CMV model than in the EHL model, yielding weaker backward-looking inflation dynamics. By comparing second moment statistics (standard deviations, correlations with output and first-order autocorrelations) of output, price inflation, wage inflation and the nominal interest rate obtained from actual data with those obtained in the two estimated models, we observe that both models provide a similar fit of the cyclical features characterizing the Great Moderation period. More important, the estimated CMV is able to reproduce a large extent of the second moment statistics of the US rate of unemployment.

Finally, this paper also makes a contribution to the calculation of the welfare cost of business cycles. The analysis is carried out using the estimated parameters of the CMV and EHL models. Our findings indicate that short-run fluctuations cause a welfare loss in the US economy measured as a permanent $0.60 \%$ of consumption in the CMV model and as a $0.31 \%$ of consumption in the EHL model. These values for the welfare cost of business cycles are much higher than the one suggested by Lucas (2003).

The paper proceeds as follows. Section 2 describes the CMV model and compares it with the EHL model. Section 3 introduces the estimation procedure and shows the parameter estimates. Section 4 presents the empirical fit of the two models whereas a robustness analysis of the CMV estimation results is carried out in Sect. 5. Next, Sect. 6 computes the welfare cost of cyclical fluctuations estimated for the two models. Section 7 concludes.

\section{The model}

This section describes a New-Keynesian model of unemployment fluctuations driven by sticky wages similar to Casares (2010). Therefore, the labor market provides employment fluctuations at the extensive margin. For that purpose, we assume indivisible labor hours as in Hansen (1985), so that workers spend a constant number of daily hours at work. Thus, variations on total hours are exclusively driven by changes in the number of employed workers. ${ }^{5}$

As in Merz (1995) and most papers of the Mortensen-Pissarides literature, the representative household is a large family and their members pool differentiated labor

\footnotetext{
4 Other well-known DSGE models without unemployment are Christiano et al. (2005), and Smets and Wouters $(2003,2007)$.

5 An inelastic supply of hours per worker has been assumed in Cooley and Hansen (1989), Merz (1995) and, more recently, Blanchard and Galí (2007).
} 
income to be evenly split up in consumption shares in a way that they all are perfectly insured against unemployment. Let us define $h$ as the constant number of hours per employee at work and $n_{t}(i)$ the number of household members working in some specific $i$-th firm. Thus, total hours worked at the $i$ firm are $n_{t}(i) h$. Assuming constant relative risk aversion, the utility function for the representative household is given by

$$
U\left(\chi_{t}, c_{t}, n_{t}^{s}(i)\right)=\exp \left(\chi_{t}\right) \frac{\left[c_{t}\right]^{1-\sigma}}{1-\sigma}-\Psi \int_{0}^{1} \frac{\left[n_{t}^{s}(i) h\right]^{1+\gamma}}{1+\gamma} d i
$$

where $\chi_{t}$ is a consumption preference shock that follows an exogenous AR(1) process, $c_{t}$ is current household's consumption, $n_{t}^{s}(i) h$ are total hours supplied in the $i$ firm, and all the firms are collected in the unit interval. Defining $\bar{\Psi}=\Psi h^{1+\gamma}$, we can rewrite the utility function as

$$
U\left(\chi_{t}, c_{t}, n_{t}^{s}(i)\right)=\exp \left(\chi_{t}\right) \frac{\left[c_{t}\right]^{1-\sigma}}{1-\sigma}-\bar{\Psi} \int_{0}^{1} \frac{\left[n_{t}^{s}(i)\right]^{1+\gamma}}{1+\gamma} d i .
$$

Regarding firms' behavior, we consider the standard Dixit and Stiglitz (1977) setup of monopolistically competitive firms with a production technology that exhibits diminishing labor returns and constant capital. There are nominal rigidities in the setting of both prices and wages, which are defined by their respective constant probabilities as in Calvo (1983) and commonly assumed in the New-Keynesian literature. Following Casares (2010), wage setting is aimed at an intertemporal matching between the number of job applicants supplied by the household and the number of jobs demanded by the firms, provided a constant number of hours per job. It leads to having unemployment as excess supply of labor at firm level. Let $\eta_{w}$ be the Calvo-type constant probability that the firm and the household cannot get together to negotiate a new wage contract. If that is the case, the nominal wage is adjusted by the indexation rule introduced below and the household is required to supply as many jobs as needed to meet demand. ${ }^{6}$ Otherwise, with a probability $1-\eta_{w}$, the firm and the household sit down to find the nominal wage that satisfies the following jobs-clearing condition ${ }^{7}$

$$
E_{t}^{\eta_{w}} \sum_{j=0}^{\infty} \beta^{j} \eta_{w}^{j}\left[n_{t+j}^{s}(i)-n_{t+j}^{d}(i)\right]=0
$$

where $n_{t+j}^{s}(i)$ and $n_{t+j}^{d}(i)$ are respectively the quantity of jobs supplied and demanded in the specific $i$ firm, $E_{t}^{\eta_{w}}$ is the rational expectation operator conditional to the lack

\footnotetext{
6 The arrival of a Calvo signal that impedes setting the jobs-clearing nominal wage would oblige the household to meet labor demand. It is a similar situation that faces the firm that cannot set the optimal price. Thus, the effective amounts of output and labor are demand determined.

${ }^{7}$ It should be noticed that in the case of fully-flexible nominal wages $\left(\eta_{w}=0\right)$, the jobs-clearing condition (2) gives a perfect matching between labor supply and labor demand, $n_{t}^{s}(i)=n_{t}^{d}(i)$. Therefore, if wage stickiness were dropped the model would deliver no unemployment fluctuations.
} 
of wage contract revisions in the future, and $\beta \in(0,1)$ is the discount factor. Firms post demand for jobs and households supply a number of job seekers. The first-order condition of the household for the supply of labor implies a constant elasticity of substitution, $1 / \gamma$, across wage-specific industries. This condition can be expressed in terms of log-deviations from steady-state values:

$$
\widehat{n}_{t}^{s}(i)=\frac{1}{\gamma}\left(\widehat{W}_{t}(i)-\widehat{W}_{t}\right)+\widehat{n}_{t}^{s},
$$

where $\widehat{W}_{t}(i)$ is the log-deviation of the $i$-firm nominal wage from its steady-state level, $\widehat{W}_{t}=\int_{0}^{1} \widehat{W}_{t}(i) d i$ is the log-deviation of the aggregate nominal wage from its steadystate level and $\widehat{n}_{t}^{s}=\int_{0}^{1} \widehat{n}_{t}^{s}(i) d i$ is the log-deviation of the aggregate labor supply from the steady-state level of employment. Meanwhile, labor demand is the amount of jobs required to produce as many units of output as demanded in the monopolistically competitive market. The production technology relates firm-specific output to the demand for total hours of labor, $n_{t}^{d}(i) h$, and an AR(1) technology shock, $z_{t}$, as follows: $y_{t}(i)=\exp \left(z_{t}\right)\left[n_{t}^{d}(i) h\right]^{1-\alpha}$ with $0<\alpha<1$. In log-deviations from steady-state, we get:

$$
\widehat{y}_{t}(i)=(1-\alpha) \widehat{n}_{t}^{d}(i)+z_{t}
$$

Combining the last expression with a log-linearized Dixit-Stiglitz demand curve commonly used in the New-Keynesian literature, we obtain

$$
\widehat{n}_{t}^{d}(i)=-\frac{\theta}{1-\alpha}\left(\widehat{P}_{t}(i)-\widehat{P}_{t}\right)+\widehat{n}_{t},
$$

where $\theta>0$ denotes the Dixit-Stiglitz elasticity of substitution and $\widehat{n}_{t}=\int_{0}^{1} \widehat{n}_{t}^{d}(i) d i$ is the aggregate log-deviation of employment from its steady-state value.

Hence, jobs-clearing wages are set whenever market frictions permit labor at the value that solves (2), provided current and future expressions of Eqs. (3) and (4), which respectively govern the evolution of supply and demand for jobs. At the firm level, we have

$$
u_{t}(i)=\widehat{n}_{t}^{s}(i)-\widehat{n}_{t}^{d}(i)
$$

that can be used for the aggregation across firms leading to the aggregate rate of unemployment

$$
u_{t}=\int_{0}^{1} u_{t}(i) d i=\widehat{n}_{t}^{s}-\widehat{n}_{t} .
$$

Moreover, the system of Eqs. (2)-(4) brings a connection between pricing behavior and wage setting at firm level (absent in standard Mortensen-Pissarides frameworks). 
The optimal price decision will be affected by the firm-specific circumstances (the history of Calvo probabilities) yielding nominal wage differentiation across firms. Meanwhile, nominal wages are set at different values depending upon particular pricing conditions. For instance, after an expansionary demand shock firms that can price optimally and hold nominal wages above the average wage will increase prices further up because they are facing higher marginal costs. In addition, firm-specific wages will be lower for a firm that has a higher price than the average because labor demand is much weaker with high prices. In particular, it can be proved that there is a positive relationship between the firm-specific relative optimal price and relative past wages, $\widehat{P}_{t}^{*}(i)=\widehat{P}_{t}^{*}+\tau_{1}\left(\widehat{W}_{t-1}(i)-\widehat{W}_{t-1}\right)$, where the $i$ index distinguishes firm-specific variables from economy-wide averages. Also, there is a negative dependence between relative wages and relative prices, $\widehat{W}_{t}(i)=\widehat{W}_{t}-\tau_{2}\left(\widehat{P}_{t}(i)-\widehat{P}_{t}\right) .8$

Unlike in Casares (2010), endogenous inertia on price and wage dynamics can be added to improve the empirical fit of the model. Thus, firms that cannot price optimally will apply a price indexation rule built as a weighted reaction to the previous rate of inflation and the steady-state rate of inflation plus a stochastic white-noise deviation:

$$
P_{t}(i)=P_{t-1}(i)\left[\left(1+\pi_{t-1}^{p}\right)^{\delta_{p}}\left(1+\pi^{p}+v_{t}^{p}\right)^{1-\delta_{p}}\right]
$$

where $\pi_{t-1}^{p}$ is economy-wide lagged inflation, $\pi^{p}$ is the steady-state rate of inflation and $v_{t}^{p}$ is a price indexation shock. The parameter $\delta_{p} \in[0,1]$ measures the weight assigned to lagged inflation in the indexation rule. The particular setting $\delta_{p}=0$ eliminates the influence of lagged inflation on the price indexation rule and leaves out the inertial dynamics of inflation.

Firms and households agree on a wage indexation rule for the nominal wage contracts that cannot be renegotiated. Similarly to prices, the wage indexation rule reflects a weighted reaction to lagged wage inflation and steady-state wage inflation plus a stochastic white-noise deviation, as follows:

$$
W_{t}(i)=W_{t-1}(i)\left[\left(1+\pi_{t-1}^{w}\right)^{\delta_{w}}\left(1+\pi^{w}+v_{t}^{w}\right)^{1-\delta_{w}}\right]
$$

where $W_{t}(i)$ is the firm-specific nominal wage set in period $t, \pi_{t-1}^{w}$ is lagged wage inflation, $\pi^{w}$ is the steady-state rate of wage inflation, and $v_{t}^{w}$ is a white-noise wage indexation shock. The parameter $\delta_{w} \in[0,1]$ accommodates the weight of lagged wage inflation in the indexation rule. If $\delta_{w}=0$, the indexation rule lacks from a backward-looking pattern.

The complete CMV model can be expressed as the following linearized system of equations:

8 Analytical expressions of $\tau_{1}$ and $\tau_{2}$ are found to be
$\tau_{1}=\frac{\left(1-\beta \eta_{p}\right) \eta_{w}}{\left(1-\beta \eta_{p} \eta_{w}\right)\left(1+\frac{\alpha \theta}{1-\alpha}+\tau_{2}\left(1-\frac{\left(1-\beta \eta_{p}\right) \eta_{w}}{1-\beta \eta_{p} \eta_{w}}\right)\right)}$ and $\tau_{2}=\frac{\gamma \theta\left(1-\beta \eta_{w}\right)}{(1-\alpha)\left(1-\beta \eta_{w} \eta_{p}\right)\left(1+\frac{\tau_{1} \beta \eta_{w} \gamma \theta}{(1-\alpha)}\left(1-\frac{\eta_{p}\left(1-\beta \eta_{w}\right)}{1-\beta \eta_{w} \eta_{p}}\right)\right)}$.

See Casares (2010) for the proof. 


$$
\begin{gathered}
\pi_{t}^{p}=\frac{\delta_{p}}{1+\beta \delta_{p}} \pi_{t-1}^{p}+\frac{\beta}{1+\beta \delta_{p}} E_{t} \pi_{t+1}^{p}+\frac{\kappa_{p}}{1+\beta \delta_{p}} \widehat{\psi}_{t}+\frac{1-\delta_{p}}{1+\beta \delta_{p}} v_{t}^{p}, \\
\widehat{\psi}_{t}=\widehat{w}_{t}-\left(\widehat{y}_{t}-\widehat{n}_{t}\right), \\
\pi_{t}^{w}=\frac{\delta_{w}}{1+\beta \delta_{w}} \pi_{t-1}^{w}+\frac{\beta}{1+\beta \delta_{w}} E_{t} \pi_{t+1}^{w}-\frac{\kappa_{w}}{1+\beta \delta_{w}} u_{t}+\frac{1-\delta_{w}}{1+\beta \delta_{w}} v_{t}^{w}, \\
\widehat{w}_{t}=\widehat{w}_{t-1}+\pi_{t}^{w}-\pi_{t}^{p}, \\
\widehat{y}_{t}=(1-\alpha) \widehat{n}_{t}+z_{t}, \\
u_{t}=\widehat{n}_{t}^{s}-\widehat{n}_{t}, \\
\widehat{y}_{t}=\frac{1}{\gamma}\left(\widehat{w}_{t}-\sigma \widehat{y}_{t}+\chi_{t}\right), \\
R_{t}=\left(1-\mu_{R}\right)\left[\mu_{\pi} \pi_{t}^{p}+\mu_{y}\left(\widehat{y}_{t}-\widehat{\bar{y}}_{t}\right)\right]+\mu_{R} R_{t-1}+\varepsilon_{t}^{R}, \\
\left(\frac{\alpha+\gamma}{1-\alpha}+\sigma\right) \widehat{\bar{y}}_{t}=\frac{1+\gamma}{1-\alpha} z_{t}+\chi_{t} .
\end{gathered}
$$

There are ten endogenous variables: the rate of price inflation, $\pi_{t}^{p}$; the rate of wage inflation, $\pi_{t}^{w}$; the real marginal cost, $\widehat{\psi}_{t}$; the real wage, $\widehat{w}_{t}$; output, $\widehat{y}_{t}$; the unemployment rate, $u_{t}$; the average labor supply, $\widehat{n}_{t}^{s}$; the average (effective) labor demand, $\widehat{n}_{t}$; the nominal interest rate, $R_{t}$; and potential (natural-rate) output $\widehat{\bar{y}}_{t}$. Variables topped with a hat symbol represent log-deviations from their respective steady-state levels, whereas the remaining variables represent the difference in levels with respect to their respective steady-state rates. Model variability comes from five exogenous shocks: $z_{t}, \chi_{t}, v_{t}^{p}, v_{t}^{w}$, and $\varepsilon_{t}^{R}$. Only the technology shock $\left(z_{t}\right)$ and the consumption preference shock $\left(\chi_{t}\right)$ are serially correlated; the other three (nominal) shocks are considered white-noise independent processes. The quasi-slope coefficients $\kappa_{p}$ and $\kappa_{w}$ have the following analytical expressions ${ }^{9}$ :

$$
\kappa_{p}=\frac{\left(1-\beta \eta_{p}\right)\left(1-\eta_{p}\right)}{\eta_{p}\left(1+\frac{\alpha \theta}{1-\alpha}+\tau_{2}\left(1-\frac{\eta_{w}\left(1-\beta \eta_{p}\right)}{1-\beta \eta_{p} \eta_{w}}\right)\right)}
$$

and

$$
\kappa_{w}=\frac{\gamma\left(1-\beta \eta_{w}\right)\left(1-\eta_{w}\right)}{\eta_{w}\left(1+\tau_{1} \frac{\beta \eta_{w} \theta \gamma}{1-\alpha}\left(1-\frac{\eta_{p}\left(1-\beta \eta_{w}\right)}{1-\beta \eta_{p} \eta_{w}}\right)\right)} .
$$

Let us briefly describe the model Eqs. (5)-(14). The price-inflation equation, (5), is a hybrid New-Keynesian Phillips curve that combines both backward and forward-looking dynamics. It is obtained from log-linearizing the first-order condition of the optimal price in a monopolistically competitive economy with Calvo-type frictions on price setting and on jobs-clearing nominal wages. Equation (6) is a log-linear definition of the real marginal cost where labor productivity is obtained

\footnotetext{
9 See the technical appendix of Casares (2010) for the proof.
} 
from the technology with diminishing marginal returns described above. Wage-inflation dynamics are governed by Eq. (7), that resembles the seminal Phillips (1958) curve because it displays a negative relationship between wage inflation and the rate of unemployment. In a similar way to price inflation, there are both backward and forward-looking components characterizing wage inflation dynamics, the former due to the assumption of indexation on lagged wage inflation. Jobs-clearing wage setting, Calvo-style sticky wages and a wage indexation rule result in the wage inflation dynamics implied by Eq. (7). Actually, sticky wages are crucial to explain unemployment fluctuations. Those non-renegotiated nominal wages deliver a mismatch between the household's supply of labor measured as the number of job seekers and the firm's demand for labor measured as the number of jobs posted, which after aggregation corresponds to our measure of the unemployment rate.

Real wage dynamics are provided by Eq. (8). We assume a Cobb-Douglas production technology with constant capital and a technology shock. It is log-linearized in Eq. (9). The rate of unemployment is endogenously defined by Eq. (10) as the logdifference between average supply of labor and the average labor demand measured as the number of jobs (extensive margin).

The labor supply function and the IS curve (Eqs. 11 and 12) are obtained from the household's optimizing behavior using the utility function specification (1). Concretely, the combination of consumption and labor first-order equations together with the market-clearing condition that equates consumption and output, leads to the labor supply Eq. (11). The IS-type Eq. (12) is obtained from log-linearizing the consumption Euler equation.

Next, monetary policy follows a Taylor (1993)-type rule with a smoothing component and an interest-rate shock described in Eq. (13). The nominal interest rate changes endogenously in response to changes in the rate of inflation, the output gap and the lagged nominal interest rate. The output gap is defined as the log-deviation between current output and potential (natural-rate) output. Finally, fluctuations of potential output are obtained from Eq. (14), which provides deviations of output from steady state if the economy were released from nominal rigidities, i.e. setting $\eta_{p}=\eta_{w}=0$.

\subsection{A comparison with EHL (2000)}

EHL (2000) introduce sticky wages in a New-Keynesian model. Staggered nominal wages reproduce the constant probability scheme of Calvo (1983)-type contracts that are applied to pricing decisions. Thus, there are both sticky prices and sticky wages à la Calvo (1983). In spite of having wage rigidities, the EHL model is a DSGE model. That is, the labor market is at equilibrium in every period. Households own a differentiated labor service that gives them market power to set the nominal wage. Letting $\eta_{w}$ be the Calvo probability that disables optimal wage setting and adding a wage indexation rule identical to the CMV model described above, fluctuations of wage inflation in the EHL model are given by the following forward-looking 
equation:

$$
\pi_{t}^{w}=\frac{\delta_{w}}{1+\beta \delta_{w}} \pi_{t-1}^{w}+\frac{\beta}{1+\beta \delta_{w}} E_{t} \pi_{t+1}^{w}+\frac{\left(1-\eta_{w}\right)\left(1-\beta \eta_{w}\right)}{\eta_{w}\left(1+\gamma \theta_{f}\right)\left(1+\beta \delta_{w}\right)}\left(\widehat{m r s_{t}}-\widehat{w}_{t}\right)+\frac{1-\delta_{w}}{1+\beta \delta_{w}} v_{t}^{w},
$$

where $\widehat{m r s_{t}}-\widehat{w}_{t}$ is the log-difference between the household's marginal rate of substitution (mrs) and the real wage, and $\theta_{f}$ is the labor demand elasticity of substitution.

Remarkably, the CMV model features a semi-loglinear relationship between the rate of unemployment and the gap that drives wage inflation fluctuations in the EHL model, $\widehat{m r s}_{t}-\widehat{w}_{t}$. Hence, inserting Eq. (11) that determines fluctuations of the labor supply in the unemployment definition (10), it yields

$$
u_{t}=\frac{1}{\gamma}\left(\widehat{w}_{t}-\sigma \widehat{y}_{t}+\chi_{t}\right)-\widehat{n}_{t} .
$$

Meanwhile, the expression for $\widehat{m r s_{t}}$ implied by the utility function specified above is ${ }^{10}$

$$
\widehat{m r s_{t}}=\gamma \widehat{n}_{t}-\chi_{t}+\sigma \widehat{y}_{t}
$$

Comparing (16) and (17), it is straightforward to obtain that

$$
\widehat{m r s_{t}}-\widehat{w}_{t}=-\gamma u_{t}
$$

which obviously is only a valid statement for the CMV model, since the EHL model lacks unemployment.

The relationship between unemployment and the mrs-wage gap implied by (18) can be substituted in the wage inflation equation of the CMV model, Eq. (7), to obtain

$$
\pi_{t}^{w}=\frac{\delta_{w}}{1+\beta \delta_{w}} \pi_{t-1}^{w}+\frac{\beta}{1+\beta \delta_{w}} E_{t} \pi_{t+1}^{w}+\frac{\kappa_{w}}{1+\beta \delta_{w}} \frac{1}{\gamma}\left(\widehat{m r s_{t}}-\widehat{w}_{t}\right)+\frac{1-\delta_{w}}{1+\beta \delta_{w}} v_{t}^{w} .
$$

Hence, the labor market structures of the CMV and EHL models are different in two aspects. First, the interpretation of aggregate labor fluctuations, $\widehat{n}_{t}$, is different. Thus, $\widehat{n}_{t}$ represents total number of hours at work in the EHL model whereas it does the total number of employed workers (employment) in the CMV model. The negative value of the labor gap in the EHL model, $-\left(\widehat{n}_{t}-\widehat{\bar{n}}_{t}\right)$, brings the log difference between

10 Provided the same specification for the instantaneous utility function used in the CMV model (see expression 1 in Sect. 2), the marginal rate of substitution between the supply of labor to the $i$-th firm and consumption is:

$$
m r s_{t}(i)=\frac{\bar{\Psi} n_{t}^{s}(i)^{\gamma}}{\exp \left(\chi_{t}\right) c_{t}^{-\sigma}} .
$$

Log-linearizing this expression, using the equilibrium condition $\widehat{c}_{t}=\widehat{y}_{t}$, and aggregating across firms lead to the expression shown in the main text. 
effective total hours and the amount that would result in an economy with flexible prices and flexible wages, and might provide a close equivalent to unemployment. ${ }^{11}$ Second, the analytical expression that governs wage inflation dynamics is different. Comparing the EHL Eq. (15) with its jobs-clearing counterpart (19), it can be noticed how the slope coefficient in (19) depends upon the value of $\kappa_{w}$ which collects the connections between pricing and wage setting. Such connections are absent in the EHL model.

Regarding the price inflation equation, firms set prices under Calvo nominal rigidities in both models. When receiving the right market signal, the optimal price depends positively on both the aggregate price level and the real marginal cost. To make the version of the EHL model used here comparable to the CMV model, it is assumed constant capital and the same price indexation rule for the cases of non-optimal pricing. When abstracting from variable capital, the real marginal cost is firm-specific which implies a flatter slope of the Phillips curve (Sbordone 2002). Thus, the Phillips curve that drives inflation dynamics in the version of the EHL model with constant capital and a price indexation rule is

$$
\pi_{t}^{p}=\frac{\delta_{p}}{1+\beta \delta_{p}} \pi_{t-1}^{p}+\frac{\beta}{1+\beta \delta_{p}} E_{t} \pi_{t+1}^{p}+\frac{\left(1-\eta_{p}\right)\left(1-\beta \eta_{p}\right)}{\eta_{p}(1+\alpha \theta /(1-\alpha))\left(1+\beta \delta_{p}\right)} \widehat{\psi}_{t}+\frac{1-\delta_{p}}{1+\beta \delta_{p}} v_{t}^{p} .
$$

The only difference with the Phillips curve of the CMV model is the slope coefficient. By comparing the slopes of (5) and (20) and noting the analytical expression that determines $\kappa_{p}$, we can conclude that the slope coefficient is lower in the CMV model. Therefore, the reaction of inflation to changes in the real marginal cost is smaller in the CMV model. This difference can again be explained by the connections between wage setting and price setting that are present in the CMV model. In short, any price increase that comes after a rise of the real marginal cost would reduce firm-specific labor demand and, subsequently, the jobs-clearing nominal wage. A falling nominal wage would partially compensate the initial increase in the real marginal cost in a way that would cut the price hike. In turn, the price level and inflation would have a weaker response to changes in the aggregate real marginal cost (lower slope coefficient).

\section{Estimation}

\subsection{Data and estimation procedure}

The CMV and EHL models are estimated using US quarterly data from the Great Moderation period (1984:1Q-2008:2Q). Indeed, this sample period has been characterized by mild fluctuations of most (both real and nominal) aggregate variables (see Stock and Watson 2002, among others). Thus, we would expect not to suffer from any important misspecification sources, such as parameter instability in both the private sector - for instance, Calvo probabilities (Moreno 2004)—and the monetary policy reactions to inflation or output (Canova 2009). Indeed, some authors argue that a sound monetary policy implementation is the main factor behind the low aggre-

$\overline{11}$ This possibility was suggested by one of the referees and it is examined below in Sect. 4 . 
gate volatility since the mid-1980's (Clarida et al. 1994). In the robustness exercises conducted below, we compare the results obtained during the Great Moderation with those found in the pre-Volcker period.

The data set includes five time series: the real Gross Domestic Product (GDP), the price inflation rate obtained from the implicit GDP deflator, the wage inflation rate obtained from nominal compensation per hour, the 3-month Treasury bill rate and the unemployment rate. Real GDP was logged and linearly detrended to extract the cyclical component of output. The data were retrieved from the Federal Reserve of St. Louis (FRED) database. In the robustness section below, we also show that results are not specific to the detrending method (or to the use of output growth instead of detrended output) as well as to the inclusion of a measure of employment in the set of variables.

We estimate the two alternative models using a now-standard two-step Bayesian procedure. ${ }^{12}$ In the first step, the $\log$ posterior function is maximized in a way that combines the prior information of the parameters with the empirical likelihood of the data. In a second step, we perform the Metropolis-Hastings algorithm to compute the posterior distribution associated with each estimated parameter. Notice that the slope coefficients in the price and wage inflation equations are implicit functions of the undetermined coefficients $\tau_{1}$ and $\tau_{2}$. These coefficients can be analytically solved through a non-linear two-equation system. We pick the positive values associated with these solutions, as implied by theory.

The selection of prior distributions for the model parameters is based on similar related studies (Smets and Wouters 2007; Gertler et al. 2008). The priors for the utility function parameters $\sigma$ and $\gamma$ are set at 2.0 and 4.0, respectively; with standard deviations 0.1 and 0.5 , respectively. The prior for the elasticity of substitution across goods $(\theta)$ is set at 6 , which implies a $20 \%$ mark-up in steady state. The prior distribution for the two indexation parameters in the price and wage inflation equations $\left(\delta_{p}, \delta_{w}\right)$ is a normal with mean 0.5 and standard deviation 0.1 . Exactly the same priors are chosen for the Calvo probabilities of price and wage adjustment $\left(\eta_{p}, \eta_{w}\right)$, implying an average duration of both wage and price contracts of two quarters. The priors of the production function parameter and the subjective time discount factor $(\alpha$ and $\beta$ ) are the standard values of 0.36 and 0.99 , respectively; with standard deviation of 0.01 . Following Gertler et al. (2008), the priors of monetary policy parameters are set at 0.75 for the endogenous persistence parameter, 1.7 for the long-run response to inflation and 0.125 for the response to cyclical output. Also following their priors, the standard deviations of the innovations to the shocks come from an inverse gamma distribution with mean and standard deviation 0.15 , whereas the autocorrelation parameters of the technology and preference shocks are set at 0.5 , with standard deviation 0.1 . A sensitivity analysis is carried out in Sect. 5.1 below by using looser prior distributions.

As is standard in the literature, we select the local stable equilibrium as the model solution. We thus disregard all the non-local explosive equilibria. Cochrane (2010) has pointed out that these equilibria should be taken into account, but we restrict our attention to the stable equilibrium, which seems the most sensible one in terms of both

12 See, for instance, Fernández-Villaverde (2010), and references therein, for an excellent review of the literature on estimation of DSGE models using Bayesian techniques. 
Table 1 Priors and estimated posteriors of structural parameters

\begin{tabular}{|c|c|c|c|c|c|c|c|c|c|}
\hline & Priors & & & Poster & & & & & \\
\hline & Distr & Mean & Std D. & $\mathrm{CMV}$ & & & EHL & & \\
\hline & & & & Mean & $5 \%$ & $95 \%$ & Mean & $5 \%$ & $95 \%$ \\
\hline$\sigma$ & Normal & 2.00 & 0.10 & 2.11 & 1.95 & 2.25 & 2.11 & 1.95 & 2.27 \\
\hline$\gamma$ & Normal & 4.00 & 0.50 & 4.66 & 3.99 & 5.35 & 4.34 & 3.78 & 4.91 \\
\hline$\theta$ & Normal & 6.00 & 0.50 & 6.18 & 5.45 & 6.83 & 6.30 & 5.81 & 6.85 \\
\hline$\theta_{f}$ & Normal & 4.00 & 0.50 & & & & 4.18 & 3.62 & 5.02 \\
\hline$\alpha$ & Normal & 0.36 & 0.01 & 0.36 & 0.34 & 0.37 & 0.36 & 0.35 & 0.37 \\
\hline$\beta$ & Normal & 0.99 & 0.01 & 0.99 & 0.97 & 1.00 & 0.99 & 0.97 & 1.00 \\
\hline$\delta_{p}$ & Normal & 0.50 & 0.10 & 0.47 & 0.36 & 0.55 & 0.59 & 0.48 & 0.69 \\
\hline$\delta_{w}$ & Normal & 0.50 & 0.10 & 0.38 & 0.29 & 0.48 & 0.33 & 0.24 & 0.44 \\
\hline$\eta_{p}$ & Beta & 0.50 & 0.10 & 0.82 & 0.78 & 0.86 & 0.88 & 0.84 & 0.91 \\
\hline$\eta_{w}$ & Beta & 0.50 & 0.10 & 0.85 & 0.81 & 0.88 & 0.82 & 0.77 & 0.87 \\
\hline$\mu_{r}$ & Beta & 0.75 & 0.10 & 0.84 & 0.80 & 0.87 & 0.83 & 0.79 & 0.86 \\
\hline$\mu_{\pi}$ & Normal & 1.70 & 0.30 & 2.00 & 1.74 & 2.36 & 2.02 & 1.67 & 2.29 \\
\hline$\mu_{y}$ & Gamma & 0.125 & 0.10 & 0.70 & 0.51 & 0.95 & 0.35 & 0.23 & 0.50 \\
\hline$\rho_{\chi}$ & Beta & 0.50 & 0.15 & 0.94 & 0.91 & 0.96 & 0.90 & 0.87 & 0.93 \\
\hline$\rho_{z}$ & Beta & 0.50 & 0.15 & 0.87 & 0.83 & 0.92 & 0.91 & 0.87 & 0.93 \\
\hline$\sigma_{p}$ & Inv Gamma & 0.15 & 0.15 & 0.43 & 0.35 & 0.53 & 0.60 & 0.43 & 0.76 \\
\hline$\sigma_{w}$ & Inv Gamma & 0.15 & 0.15 & 1.12 & 0.90 & 1.33 & 0.95 & 0.79 & 1.12 \\
\hline$\sigma_{r}$ & Inv Gamma & 0.15 & 0.15 & 0.16 & 0.15 & 0.18 & 0.15 & 0.13 & 0.16 \\
\hline$\sigma_{z}$ & Inv Gamma & 0.15 & 0.15 & 0.44 & 0.38 & 0.49 & 0.45 & 0.39 & 0.49 \\
\hline$\sigma_{\chi}$ & Inv Gamma & 0.15 & 0.15 & 2.46 & 1.76 & 3.08 & 1.76 & 1.44 & 1.98 \\
\hline
\end{tabular}

our model -which is in deviations from steady-states- and both country and sample of analysis considered. In case of equilibrium indeterminacy, the estimation procedure selects the solution associated with the smallest roots (generalized eigenvalues), known as the MOD solution, suggested by Blanchard and Kahn (1980) and used by McCallum (2004), among other authors. Finally, we note that monetary policy parameters are well identified in the context of this standard model solution, given that the monetary policy shock is an i.i.d. process and no stochastic intercept appears in the policy rule.

\subsection{Estimation results}

Table 1 reports the prior and posterior distributions of each parameter in our proposed CMV model, together with the 5 and $95 \%$ quantiles of the posterior distribution. This table also compares the posterior distributions with those obtained -using the same priors- from the estimated version of the EHL model described in Sect. 2. 
Table 1 shows that all parameter estimates are statistically different from zero, with statistical confidence bands varying in size, but small overall. In several cases, the posteriors are close to the priors, where in some instances, they are significantly distant. In particular, the posterior of the "deep" parameters (preferences, technology and market structure) are very close to their respective priors. The estimate for the curvature of the consumption utility function $\sigma$ is 2.11 , showing a moderate sensibility of output to changes in the real interest rate. As for the labor disutility parameter $\gamma$, it is estimated at 4.66, implying a relatively low labor supply elasticity consistent with most microeconomic evidence. The parameter measuring the Dixit-Stiglitz demand elasticity, $\theta$, is estimated to be 6.18. The capital share in the production function, $\alpha$, matches the prior level of 0.36 , the same as the time discount parameter, $\beta$, which remains at 0.99 . We find values of the indexation parameters in the price and wage inflation equations below, but close to the prior value of 0.50 . In contrast, the parameters that measure the Calvo-type price and wage rigidities are estimated to be around 0.84 , much higher than the 0.5 prior, implying high price and wage rigidities. ${ }^{13}$ These values for the Calvo parameters are somewhat higher than those obtained for the Great Moderation by Smets and Wouters (2007) in their New-Keynesian model with sticky wages $\grave{a}$ la EHL, i.e. without unemployment. ${ }^{14}$ The price adjustment parameter is similar to that estimated by Gertler et al. (2008), whereas our estimate of the wage adjustment parameter is quite higher (they estimate it to be 0.71 ). The values obtained for the monetary policy parameters are in line with those reported in the literature for the period considered: a high coefficient on the lagged interest rate $(0.84)$, a large interest rate response to inflation (2.00) and a moderate response to output (0.70). Finally, the size of the innovations to the consumption preference shock (that shifts the IS curve) is significantly higher than those of the other shocks.

Table 1 also shows that the parameter estimates of the CMV model are quite similar to those obtained in the estimation of the EHL model. ${ }^{15}$ Indeed, the confidence intervals associated with each parameter estimate, obtained from the two models, always overlap except for the output gap coefficient in the policy rule, $\mu_{y}$, showing that parameter estimate differences between the two models are not statistically significant. ${ }^{16}$ Thus,

\footnotetext{
13 Nevertheless, sticky prices do not imply firm-specific constant prices in the models. It should be recalled that firms that cannot price optimally will adjust current prices by applying the indexation rule that takes into account lagged inflation, the steady-state rate of inflation and the price indexation shock. With a similar wage indexation rule, nominal wages also change every period. A greater extent of nominal rigidities result in a larger fraction of price/wage adjustment that follow the indexation rule.

14 Apparently, a large extent of both price and wage stickiness might seem counterintuitive during the Great Moderation period. However, the low-inflation scenario featuring this period would reduce variability on relative prices and, therefore, the average cost of deviating from optimal pricing. Thus, the presence of menu costs or information costs could more easily postpone the search of the optimal price during the Great Moderation. The high estimates of $\eta_{p}$ found here may capture this effect.

15 In the estimation of the EHL model, the US time series of total hours was used in replacement of the rate of unemployment, which is absent in that model. Thus, the time series of "Hours of All Persons in the Nonfarm Business Sector" was logged and linearly detrended to extract the business cycle component that was added to the set of observable variables. By doing so, we have the same number of observable variables and shocks across models.
}

16 We carry out below in Sect. 5.1 a sensitivity analysis of the results from the estimation of the two models by considering looser prior distributions. Parameter estimates in the CMV model are rather robust. However, 
the New Keynesian Phillips curve in the two models (Eq. 5 in the CMV model and Eq. 20 for the EHL model) displays a lagged inflation coefficient with a lower value than that of the expected next period's inflation coefficient; the lagged inflation coefficient is around $1 / 3$ and the expected inflation coefficient is near $2 / 3$. Therefore, inflation dynamics are more forward-looking than backward-looking in the two estimated models. Moreover, model estimates imply that the Phillips curve coefficients on the gap between the real wage and labor productivity are almost identical across models (i.e. these are 0.0029 and 0.0024 in the CMV and EHL models, respectively).

Apart from these similarities, there are some differences that deserve discussion. First, the estimate of the backward-looking parameter $\delta_{p}$ for inflation dynamics is lower in our proposed CMV model (0.47) compared to the figure obtained in the EHL model (0.59). Second, the EHL estimates imply somewhat lower wage rigidities, but higher price rigidities. Third, the estimates of the monetary policy rule parameters are rather similar, with a higher output response in the CMV model. Fourth, the slope of the comparable wage inflation equations is rather higher in Eq. 19 from the CMV model (0.0093) than in Eq. 15 from the EHL model (0.0022), which indicates a stronger responsiveness of wage inflation to the $\widehat{m r s}_{t}-\widehat{w}_{t}$ gap in the CMV model. Finally, the standard deviation of the innovations to price inflation shocks is smaller in the CMV model, whereas the standard deviation of the innovations to consumption preference (IS) shocks is significantly lower in the EHL model.

\section{Empirical fit}

This section compares the performance of CMV and EHL models along three dimensions. First, we analyze the ability of the two models to reproduce business cycle statistics obtained from actual data. Second, we study the contribution of each structural shock in explaining the total variance decomposition of macroeconomic variables. Finally, we carry out an impulse-response analysis.

\subsection{Second-moment statistics}

Table 2 shows second-moment statistics obtained from actual US data (first panel), and the ones found in both the estimated CMV (second panel) and EHL (third panel) models. The fourth panel exhibits the second-moment statistics obtained from the estimated CMV with the more diffuse prior distributions discussed in Sect. 5.1. In general, the two models do a good job in reproducing the cyclical features of the data. Thus, they both capture the volatility of output, the nominal interest rate and wage inflation and the low volatility of price inflation. Moreover, the two models replicate reasonably well the first-order autocorrelation of all variables. However, the CMV model

Footnote 16 continued

EHL model estimates substantially change under the alternative priors. We have considered the tight prior distribution as the benchmark case so as to focus on the different dynamic features exhibited by the CMV and EHL models. In this way we expect to distinguish those intrinsic different dynamics featured by the two models from those driven by different parameter estimates. 
Table 2 Business cycle statistics: Linear Trend

\begin{tabular}{|c|c|c|c|c|c|c|}
\hline & $\widehat{y}$ & $\pi^{p}$ & $\pi^{w}$ & $R$ & $u$ & $-(n-\bar{n})$ \\
\hline \multicolumn{7}{|l|}{ US data, 1984:1-2008:2 } \\
\hline Standard deviation & 1.60 & 0.25 & 0.60 & 0.54 & 1.06 & - \\
\hline Correlation with output & 1.0 & 0.03 & 0.25 & 0.23 & -0.59 & - \\
\hline Autocorrelation & 0.95 & 0.48 & 0.15 & 0.97 & 0.98 & - \\
\hline \multicolumn{7}{|l|}{ Estimated CMV model } \\
\hline Standard deviation & 1.30 & 0.26 & 0.66 & 0.41 & 0.98 & \\
\hline Correlation with output & 1.0 & 0.11 & 0.18 & 0.15 & -0.48 & \\
\hline Autocorrelation & 0.89 & 0.51 & 0.31 & 0.91 & 0.72 & \\
\hline \multicolumn{7}{|l|}{ Estimated EHL model } \\
\hline Standard deviation & 1.30 & 0.28 & 0.63 & 0.35 & - & 1.30 \\
\hline Correlation with output & 1.0 & -0.19 & 0.04 & -0.21 & - & -0.58 \\
\hline Autocorrelation & 0.88 & 0.56 & 0.29 & 0.89 & - & 0.83 \\
\hline \multicolumn{7}{|c|}{ Estimated CMV model with more diffuse priors } \\
\hline Standard deviation & 1.44 & 0.28 & 0.66 & 0.42 & 0.91 & \\
\hline Correlation with output & 1.0 & -0.01 & 0.12 & -0.02 & -0.42 & \\
\hline Autocorrelation & 0.92 & 0.58 & 0.29 & 0.93 & 0.77 & \\
\hline
\end{tabular}

outperforms the EHL model in two important dimensions. First, the CMV reproduces the mildly cyclical correlation of the nominal interest rate and price inflation, while the EHL model gives a slightly negative correlation of these variables with output. Second, and more importantly, the CMV model endogenously explains unemployment fluctuations, unlike the EHL model. Indeed, the CMV model does a good job in reproducing business cycle statistics on volatility and correlation with output that feature US unemployment rate. Perhaps, the only significant discrepancy is that the CMV model underpredicts a bit the observed unemployment rate persistence.

The EHL model provides a labor gap measure, which is arguably comparable to actual unemployment data. Thus, the negative labor gap obtained from the estimated EHL model is more volatile than US unemployment rate but provides a good matching for the negative correlation with output and the serial autocorrelation of unemployment.

\subsection{Variance decomposition}

Tables 3 and 4 show the long-run variance decomposition (100-period ahead forecast) for the CMV and the EHL models, respectively. The two models show similar sources of variability in business cycle fluctuations. Thus, around $60 \%$ of output variability is driven by IS shocks, $\chi$, whereas productivity innovations, $z$, explain nearly $1 / 3$ of output fluctuations in both models. Monetary policy (interest-rate) shocks take between 6\% (CMV model) and 9\% (EHL model) of the output variance decomposition and nominal shocks on prices and wages play a very minor role in both cases. Potential output only varies with real shocks as the models feature nominal shocks are 
Table 3 Variance decomposition in estimated CMV model

\begin{tabular}{|c|c|c|c|c|c|}
\hline & \multicolumn{5}{|l|}{ Shocks } \\
\hline & $v^{p}$ & $v^{w}$ & $\varepsilon^{R}$ & $z$ & $\chi$ \\
\hline Output & 0.0201 & 0.0034 & 0.0612 & 0.3164 & 0.5988 \\
\hline Potential output & 0.0000 & 0.0000 & 0.0000 & 0.6078 & 0.3922 \\
\hline Labor supply & 0.0104 & 0.0818 & 0.0104 & 0.0722 & 0.8252 \\
\hline Employment (jobs) & 0.0281 & 0.0049 & 0.0866 & 0.0847 & 0.7957 \\
\hline Unemployment & 0.0610 & 0.2017 & 0.3626 & 0.0637 & 0.3109 \\
\hline Real wage & 0.2054 & 0.6277 & 0.0502 & 0.0287 & 0.0879 \\
\hline Price inflation & 0.7624 & 0.0479 & 0.0102 & 0.0313 & 0.1482 \\
\hline Wage inflation & 0.0125 & 0.9002 & 0.0277 & 0.0045 & 0.0551 \\
\hline Nominal interest rate & 0.0722 & 0.0129 & 0.2221 & 0.1266 & 0.5662 \\
\hline
\end{tabular}

Table 4 Variance decomposition in estimated EHL model

\begin{tabular}{|c|c|c|c|c|c|}
\hline & \multicolumn{5}{|l|}{ Shocks } \\
\hline & $v^{p}$ & $v^{w}$ & $\varepsilon^{R}$ & $z$ & $\chi$ \\
\hline Output & 0.0603 & 0.0392 & 0.0891 & 0.2815 & 0.5298 \\
\hline Potential output & 0.0000 & 0.0000 & 0.0000 & 0.7838 & 0.2162 \\
\hline Labor (Total hours) & 0.0753 & 0.0477 & 0.1109 & 0.1089 & 0.6572 \\
\hline Labor gap & 0.2411 & 0.0074 & 0.2026 & 0.1400 & 0.4089 \\
\hline MRS & 0.1844 & 0.1162 & 0.2729 & 0.0475 & 0.3790 \\
\hline Real wage & 0.2582 & 0.7056 & 0.0044 & 0.0230 & 0.0088 \\
\hline Price inflation & 0.8256 & 0.1201 & 0.0029 & 0.0248 & 0.0266 \\
\hline Wage inflation & 0.0055 & 0.9808 & 0.0028 & 0.0017 & 0.0092 \\
\hline Nominal interest rate & 0.2143 & 0.0781 & 0.3131 & 0.1231 & 0.2714 \\
\hline
\end{tabular}

neutral with fully-flexible prices and wages. Technology shocks are the main source of potential output fluctuations with variance shares between $60 \%$ (CMV model) and $80 \%$ (EHL model). Consumption preference (IS) shocks explain the rest of potential output variability through their effect on labor supply shifts. Also in both models, the variability of effective employment is mostly explained by demand-side shocks such as innovations in the IS curves and, in a much lower extent, by technology innovations and interest-rate shocks. Meanwhile, price and wage inflation variances are almost entirely determined by their own cost-push shocks ( $v^{p}$ and $v^{w}$, respectively).

The models disagree in the variance decomposition of the nominal interest rate. Thus, the movements in the nominal interest rate are explained by IS innovations (57\%), monetary policy shocks $(22 \%)$ and technology shocks (13\%) in the CMV model. By contrast, IS shocks have a much lower share (27\%) as sources of variability of nominal interest rate in the EHL model, whereas price indexation shocks also take a significant share $(21 \%)$.

Finally, the variance decomposition of unemployment fluctuations is only reported in the CMV. The EHL model includes the labor gap, $\widehat{n}_{t}-\widehat{\bar{n}}_{t}$, for a comparison. 

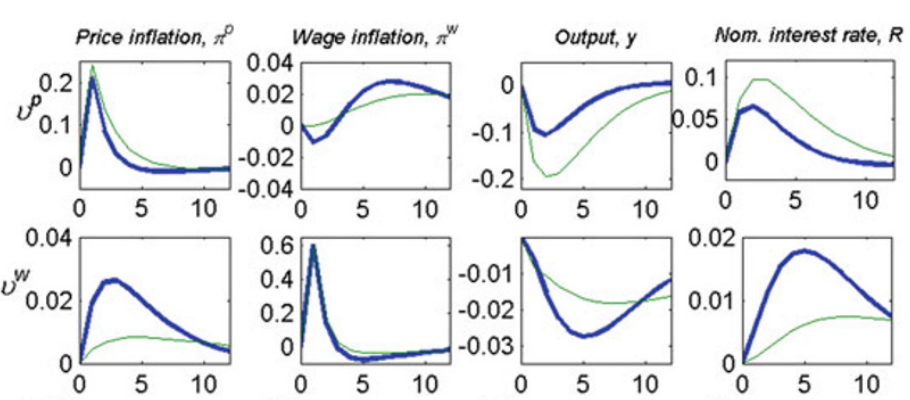

Unemployment $u$ (CMV)
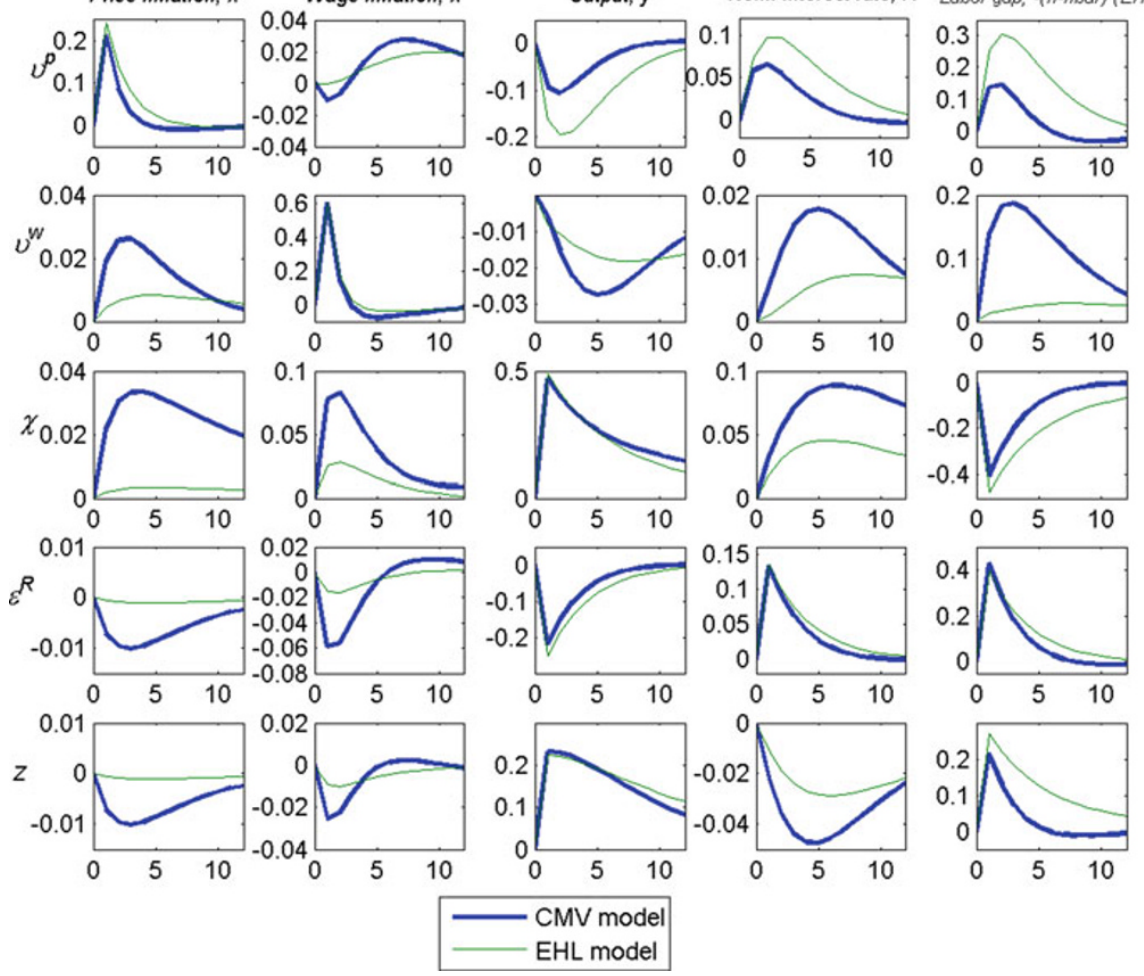

Fig. 1 Impulse response functions from one standard deviation of a price indexation shock $\left(v^{p}\right)$, a wage indexation shock $\left(v^{w}\right)$, an IS shock $(\chi)$, a monetary policy shock $\left(\varepsilon^{R}\right)$, and a technology shock $(z)$

As Table 3 shows, the CMV model reveals quite a dispersion in the sources of unemployment variability. The results indicate that much of the unemployment fluctuations are due to shocks that shift the aggregate demand. Thus, IS shocks are responsible for $31 \%$ of unemployment variability and monetary policy shocks justify $36 \%$ of changes in unemployment. Regarding supply-side innovations, cost-push shocks on wage setting, $v^{w}$, explain other $20 \%$ of fluctuations of unemployment, whereas both technology innovations and cost-push shocks on price setting, $v^{p}$, only contribute to explain $6 \%$ of unemployment variability. In the EHL model (Table 4), the variability of the labor gap, $\widehat{n}_{t}-\widehat{\bar{n}}_{t}$, is more influenced by price indexation shocks while wage indexation shocks give a negligible share in its variance decomposition. Technology shocks take $14 \%$ of the variance decomposition of the labor gap, more than doubling that of unemployment in the CMV model.

\subsection{Impulse-response functions}

Figure 1 shows the estimated impulse responses to the five structural shocks in the CMV and EHL models. The shock impulse has been normalized to one standard deviation of the innovation in all cases. The responses of output are very similar in reaction 
to all shocks except for the price indexation shock, which results in a fall of output that is half in size in the CMV model compared to the EHL model. Some other differences across models can be noticed when observing Fig. 1. For instance, the responses of price inflation to a wage inflation shock, an IS shock, an interest-rate shock and a technology shock are larger in the CMV model than in the EHL model. These differences are translated to more aggressive reactions of the nominal interest rate (as implied by the Taylor-type policy rule) in the CMV model. More importantly, the CMV model explains how unemployment reacts to alternative shocks. As expected, cost-push shocks on either prices and wages result in an increase of unemployment, a positive IS shock reduces it and a contractionary monetary policy shock brings a higher rate of unemployment as the nominal interest rate rises. In line with the empirical findings of Galí (1999), there is a countercyclical response of the unemployment rate after a positive productivity shock, though it quickly returns to the steady-state rate as shown in Fig. 1. Finally, unemployment in the CMV model and the negative labor gap in the EHL model show a pattern of close comovement in the responses to technology, IS, and interest-rate shocks (see last column of Fig. 1). With cost-push shocks, unemployment reacts more aggressively than the labor gap after a wage indexation shocks, whereas the opposite is found after a price indexation shock.

\section{Robustness analysis}

This section analyzes the robustness of the empirical evidence reported in the previous section along four important dimensions. First, we re-estimate the two models by imposing looser prior distributions. Second, we consider three additional alternative measures for the cyclical component of output. Third, we include US data of payroll employment in addition to the five time series studied in the estimation of the CMV model. Finally, we estimate the model using data from the pre-Volcker period and compare the estimation results with those found for the Great Moderation.

\subsection{Alternative priors}

This subsection studies the sensitivity of estimation results to more diffuse prior distributions. More precisely, we consider less tight priors for those parameters whose posterior mean estimates in the benchmark case are close to their respective prior mean, such as the relative risk aversion parameter, $\sigma$, and the Frisch elasticity parameter, $\gamma$. Moreover, we consider a wider prior distribution range for parameters characterizing shock processes. Table 5 shows the estimation results for the two models. Parameter estimates from the CMV model are in general robust to the alternative prior distributions. In particular, the Calvo probabilities and indexation parameters, as well as the policy rule parameters are not sensitive to the alternative priors. However, the estimates of these parameters in the EHL model turn out to be quite sensitive to the choice of priors.

The second-moment statistics obtained from the estimated CMV with the more diffuse prior distributions are displayed in the bottom panel of Table 2. There are rather 
Table 5 Estimated posteriors of structural parameters with alternative priors

\begin{tabular}{|c|c|c|c|c|c|c|c|c|c|}
\hline & \multicolumn{3}{|l|}{ Priors } & \multicolumn{6}{|c|}{ Posteriors } \\
\hline & \multirow[t]{2}{*}{ Distr } & \multirow[t]{2}{*}{ Mean } & \multirow[t]{2}{*}{ Std D. } & \multicolumn{3}{|l|}{ CMV } & \multicolumn{3}{|l|}{ EHL } \\
\hline & & & & Mean & $5 \%$ & $95 \%$ & Mean & $5 \%$ & $95 \%$ \\
\hline$\sigma$ & Normal & 2.00 & 0.50 & 3.12 & 2.49 & 3.73 & 1.89 & 1.30 & 2.49 \\
\hline$\gamma$ & Normal & 4.00 & 0.75 & 5.29 & 4.31 & 6.22 & 4.04 & 2.90 & 5.18 \\
\hline$\theta$ & Normal & 6.00 & 1.50 & 7.32 & 5.08 & 9.64 & 6.45 & 4.08 & 8.77 \\
\hline$\theta_{f}$ & Normal & 4.00 & 1.50 & & & & 3.98 & 1.59 & 6.49 \\
\hline$\alpha$ & Normal & 0.36 & 0.05 & 0.28 & 0.20 & 0.35 & 0.35 & 0.34 & 0.37 \\
\hline$\beta$ & Normal & 0.99 & 0.01 & 0.99 & 0.97 & 1.01 & 0.99 & 0.97 & 1.00 \\
\hline$\delta_{p}$ & Normal & 0.50 & 0.15 & 0.48 & 0.33 & 0.61 & 0.60 & 0.47 & 0.73 \\
\hline$\delta_{w}$ & Normal & 0.50 & 0.15 & 0.32 & 0.16 & 0.49 & 0.60 & 0.47 & 0.71 \\
\hline$\eta_{p}$ & Beta & 0.50 & 0.10 & 0.82 & 0.77 & 0.87 & 0.59 & 0.52 & 0.67 \\
\hline$\eta_{w}$ & Beta & 0.50 & 0.10 & 0.86 & 0.82 & 0.89 & 0.83 & 0.77 & 0.90 \\
\hline$\mu_{r}$ & Beta & 0.75 & 0.10 & 0.86 & 0.82 & 0.89 & 0.83 & 0.78 & 0.88 \\
\hline$\mu_{\pi}$ & Normal & 1.70 & 0.30 & 1.86 & 1.46 & 2.23 & 1.11 & 0.80 & 1.41 \\
\hline$\mu_{y}$ & Gamma & 0.125 & 0.10 & 0.64 & 0.35 & 0.92 & 0.62 & 0.34 & 0.89 \\
\hline$\rho_{\chi}$ & Beta & 0.50 & 0.20 & 0.93 & 0.91 & 0.96 & 0.92 & 0.89 & 0.97 \\
\hline$\rho_{z}$ & Beta & 0.50 & 0.20 & 0.91 & 0.85 & 0.97 & 0.96 & 0.91 & 1.00 \\
\hline$\sigma_{p}$ & Inv Gamma & 0.15 & 2.00 & 0.44 & 0.30 & 0.57 & 1.13 & 0.71 & 1.49 \\
\hline$\sigma_{w}$ & Inv Gamma & 0.15 & 2.00 & 1.02 & 0.70 & 1.33 & 1.41 & 0.93 & 1.83 \\
\hline$\sigma_{r}$ & Inv Gamma & 0.15 & 2.00 & 0.15 & 0.13 & 0.17 & 0.14 & 0.12 & 0.16 \\
\hline$\sigma_{z}$ & Inv Gamma & 0.15 & 2.00 & 0.50 & 0.39 & 0.60 & 0.75 & 0.66 & 0.84 \\
\hline$\sigma_{\chi}$ & Inv Gamma & 0.15 & 2.00 & 2.57 & 1.85 & 3.20 & 3.14 & 2.21 & 4.03 \\
\hline
\end{tabular}

The prior distributions used in the estimation procedures of the two models are identical, but the standard deviation of the prior distribution associated with parameter $\alpha$. More precise, the standard deviation assumed for the EHL is the one considered in the benchmark case because a less tight prior distribution, as the one considered in the CMV model, leads to unreasonable estimates of $\alpha$ and many other parameters

similar to those obtained under the benchmark prior distributions, which are displayed in the second panel of Table 2.

\subsection{Output filters}

As emphasized by Canova and Ferroni (2009), among other authors, the dynamic properties of estimated macro models can vary depending on the filter used for output. We now show that our parameter estimates are robust across filtering schemes. Table 6 displays the parameter estimates of the CMV model under three alternative definitions of cyclical output. The first definition is obtained implementing a quadratic-trend decomposition. The second is given by Hodrick-Prescott (HP) filter. Finally, the third considers directly the rate of growth of real GDP, which also captures the high frequency fluctuations of output. The estimation results are very similar for the four definitions of 
Table 6 Estimates under alternative cyclical components of output

\begin{tabular}{|c|c|c|c|c|c|c|c|c|c|}
\hline & \multicolumn{3}{|c|}{ Quadratic } & \multicolumn{3}{|l|}{$\mathrm{HP}$} & \multicolumn{3}{|c|}{ Growth rate } \\
\hline & Mean & $5 \%$ & $95 \%$ & Mean & $5 \%$ & $95 \%$ & Mean & $5 \%$ & $95 \%$ \\
\hline$\sigma$ & 2.11 & 1.98 & 2.24 & 2.09 & 1.94 & 2.27 & 2.08 & 1.97 & 2.29 \\
\hline$\gamma$ & 4.52 & 3.81 & 4.99 & 4.76 & 4.09 & 5.40 & 4.72 & 4.13 & 5.34 \\
\hline$\theta$ & 6.20 & 5.39 & 6.92 & 6.09 & 5.39 & 6.86 & 6.05 & 5.35 & 6.79 \\
\hline$\alpha$ & 0.36 & 0.34 & 0.37 & 0.36 & 0.34 & 0.37 & 0.36 & 0.34 & 0.37 \\
\hline$\beta$ & 0.99 & 0.97 & 1.00 & 0.99 & 0.97 & 1.00 & 0.99 & 0.97 & 1.00 \\
\hline$\delta_{p}$ & 0.45 & 0.33 & 0.54 & 0.44 & 0.35 & 0.51 & 0.47 & 0.37 & 0.60 \\
\hline$\delta_{w}$ & 0.36 & 0.26 & 0.43 & 0.41 & 0.29 & 0.53 & 0.36 & 0.24 & 0.50 \\
\hline$\eta_{p}$ & 0.82 & 0.79 & 0.87 & 0.82 & 0.78 & 0.85 & 0.82 & 0.78 & 0.86 \\
\hline$\eta_{w}$ & 0.85 & 0.82 & 0.88 & 0.84 & 0.81 & 0.87 & 0.86 & 0.83 & 0.89 \\
\hline$\mu_{r}$ & 0.85 & 0.82 & 0.88 & 0.84 & 0.81 & 0.88 & 0.86 & 0.83 & 0.88 \\
\hline$\mu_{\pi}$ & 1.97 & 1.55 & 2.48 & 1.86 & 1.58 & 2.21 & 1.98 & 1.66 & 2.32 \\
\hline$\mu_{y}$ & 0.73 & 0.47 & 0.94 & 0.70 & 0.46 & 0.89 & 0.73 & 0.46 & 0.99 \\
\hline$\rho_{\chi}$ & 0.94 & 0.91 & 0.96 & 0.93 & 0.90 & 0.96 & 0.94 & 0.92 & 0.96 \\
\hline$\rho_{z}$ & 0.85 & 0.78 & 0.91 & 0.81 & 0.77 & 0.86 & 0.89 & 0.83 & 0.93 \\
\hline$\sigma_{p}$ & 0.41 & 0.34 & 0.50 & 0.39 & 0.33 & 0.45 & 0.44 & 0.33 & 0.57 \\
\hline$\sigma_{w}$ & 1.07 & 0.90 & 1.30 & 1.21 & 0.90 & 1.53 & 1.07 & 0.82 & 1.33 \\
\hline$\sigma_{r}$ & 0.16 & 0.14 & 0.18 & 0.17 & 0.15 & 0.21 & 0.16 & 0.13 & 0.18 \\
\hline$\sigma_{z}$ & 0.45 & 0.36 & 0.51 & 0.41 & 0.36 & 0.47 & 0.49 & 0.40 & 0.57 \\
\hline$\sigma_{\chi}$ & 2.38 & 1.69 & 2.84 & 2.14 & 1.65 & 2.54 & 2.37 & 1.74 & 2.81 \\
\hline
\end{tabular}

output cyclical component studied. Moreover, the cyclical features of the CMV model analyzed in Sect. 4 are also robust to the use of alternative cyclical components. ${ }^{17}$

\subsection{Introducing employment and a labor supply shock}

The benchmark estimation of the CMV model considers only the rate of unemployment time series as the single variable describing labor market capacity. By contrast, the EHL model estimation includes a measure of labor (total hours) instead of unemployment rate. In this subsection, we consider US data of payroll employment in addition to the five time series studied in the benchmark case. The inclusion of an additional time series forces us to introduce an additional shock. ${ }^{18}$ In particular, we introduce an autocorrelated labor supply (disutility) shock, $\zeta_{t}$, that would appear in equations

\footnotetext{
17 Not shown due to space limitations. These results are available upon request from the authors.

18 As discussed by Ireland (2004), there is a long-standing tradition of introducing additional disturbances into DSGE models until the number of shocks equals the number of data series used in estimation. The reason is that models of this type are quite stylized and introduce fewer shocks than observable variables, which implies that models are stochastically singular. That is, the model implies that certain combinations of endogenous variables are deterministic. If these combinations do not hold in the data, any approach that attempts to estimate the complete model will fail.
} 
Table 7 Estimation results using Employment time series

\begin{tabular}{|c|c|c|c|c|c|c|}
\hline & \multicolumn{3}{|l|}{ Priors } & \multicolumn{3}{|c|}{ Posteriors } \\
\hline & \multirow[t]{2}{*}{ Distr } & \multirow[t]{2}{*}{ Mean } & \multirow[t]{2}{*}{ Std D. } & \multicolumn{3}{|l|}{$\mathrm{CMV}$} \\
\hline & & & & Mean & $5 \%$ & $95 \%$ \\
\hline$\sigma$ & Normal & 2.00 & 0.10 & 2.11 & 1.97 & 2.21 \\
\hline$\gamma$ & Normal & 4.00 & 0.50 & 5.64 & 5.23 & 6.36 \\
\hline$\theta$ & Normal & 6.00 & 0.50 & 6.30 & 5.58 & 7.37 \\
\hline$\alpha$ & Normal & 0.36 & 0.01 & 0.35 & 0.34 & 0.37 \\
\hline$\beta$ & Normal & 0.99 & 0.01 & 0.99 & 0.97 & 1.01 \\
\hline$\delta_{p}$ & Normal & 0.50 & 0.10 & 0.57 & 0.44 & 0.73 \\
\hline$\delta_{w}$ & Normal & 0.50 & 0.10 & 0.39 & 0.31 & 0.48 \\
\hline$\eta_{p}$ & Beta & 0.50 & 0.10 & 0.78 & 0.73 & 0.82 \\
\hline$\eta_{w}$ & Beta & 0.50 & 0.10 & 0.83 & 0.81 & 0.87 \\
\hline$\mu_{r}$ & Beta & 0.75 & 0.10 & 0.80 & 0.77 & 0.83 \\
\hline$\mu_{\pi}$ & Normal & 1.70 & 0.30 & 1.78 & 1.60 & 2.13 \\
\hline$\mu_{y}$ & Gamma & 0.125 & 0.10 & 0.57 & 0.36 & 0.72 \\
\hline$\rho_{\chi}$ & Beta & 0.50 & 0.15 & 0.89 & 0.86 & 0.91 \\
\hline$\rho_{z}$ & Beta & 0.50 & 0.15 & 0.94 & 0.91 & 0.96 \\
\hline$\rho_{\zeta}$ & Beta & 0.50 & 0.15 & 0.96 & 0.95 & 0.98 \\
\hline$\sigma_{p}$ & Inv Gamma & 0.15 & 0.15 & 0.60 & 0.38 & 0.89 \\
\hline$\sigma_{y}$ & Inv Gamma & 0.15 & 0.15 & 1.12 & 0.92 & 1.23 \\
\hline$\sigma_{r}$ & Inv Gamma & 0.15 & 0.15 & 0.17 & 0.15 & 0.19 \\
\hline$\sigma_{z}$ & Inv Gamma & 0.15 & 0.15 & 0.44 & 0.39 & 0.48 \\
\hline$\sigma_{\chi}$ & Inv Gamma & 0.15 & 0.15 & 1.58 & 1.31 & 1.87 \\
\hline$\sigma_{\zeta}$ & Inv Gamma & 0.15 & 0.15 & 1.85 & 1.61 & 2.05 \\
\hline
\end{tabular}

governing fluctuations on both labor supply, (11), and potential output, (14). Table 7 shows the estimation results using the set of six time series that includes both the rate of unemployment and payroll employment. They are again quantitatively similar to those obtained in the benchmark model reported in Table 1.

\subsection{Pre-Volcker period (1957:Q1-1979:Q2)}

This subsection analyzes the pre-Volcker period. Table 8 shows the estimation results in the CMV and EHL models. Following Smets and Wouters (2007), the pre-Volcker sample starts in 1957 and finishes right before the arrival of Paul Volcker as Federal Reserve chairman, who introduced changes in the operating procedures at the Fed. When comparing these estimation results with those obtained for the Great Moderation data set, it is useful to distinguish four sets of parameters. The first is composed by the so called deep parameters $\left(\sigma, \gamma, \theta, \theta_{e h l}, \alpha\right.$ and $\left.\beta\right)$. The estimates are robust across models and samples. The second set is formed by the indexation parameters $\left(\delta_{p}\right.$ and $\left.\delta_{w}\right)$ and Calvo parameters $\left(\eta_{p}\right.$ and $\left.\eta_{w}\right)$. The indexation parameters were higher in the 
Table 8 Estimation results for the pre-Volcker period (1957-1979)

\begin{tabular}{|c|c|c|c|c|c|c|c|c|c|}
\hline & \multicolumn{3}{|l|}{ Priors } & \multicolumn{6}{|c|}{ Posteriors } \\
\hline & \multirow[t]{2}{*}{ Distr. } & \multirow[t]{2}{*}{ Mean } & \multirow[t]{2}{*}{ Std D. } & \multicolumn{3}{|l|}{ CMV } & \multicolumn{3}{|l|}{ EHL } \\
\hline & & & & Mean & $5 \%$ & $95 \%$ & Mean & $5 \%$ & $95 \%$ \\
\hline$\sigma$ & Normal & 2.00 & 0.10 & 2.00 & 1.83 & 2.14 & 1.99 & 1.87 & 2.16 \\
\hline$\gamma$ & Normal & 4.00 & 0.50 & 4.04 & 3.24 & 4.68 & 4.14 & 3.39 & 5.13 \\
\hline$\theta$ & Normal & 6.00 & 0.50 & 6.31 & 5.05 & 7.16 & 5.95 & 5.43 & 6.63 \\
\hline$\theta_{f}$ & Normal & 4.00 & 0.50 & & & & 3.87 & 2.99 & 4.46 \\
\hline$\alpha$ & Normal & 0.36 & 0.01 & 0.35 & 0.34 & 0.37 & 0.35 & 0.34 & 0.36 \\
\hline$\beta$ & Normal & 0.99 & 0.01 & 0.98 & 0.97 & 1.00 & 0.99 & 0.98 & 0.99 \\
\hline$\delta_{p}$ & Normal & 0.50 & 0.10 & 0.61 & 0.49 & 0.76 & 0.55 & 0.44 & 0.67 \\
\hline$\delta_{w}$ & Normal & 0.50 & 0.10 & 0.52 & 0.46 & 0.61 & 0.57 & 0.48 & 0.68 \\
\hline$\eta_{p}$ & Beta & 0.50 & 0.10 & 0.71 & 0.63 & 0.79 & 0.58 & 0.52 & 0.62 \\
\hline$\eta_{w}$ & Beta & 0.50 & 0.10 & 0.92 & 0.89 & 0.95 & 0.85 & 0.84 & 0.85 \\
\hline$\mu_{r}$ & Beta & 0.75 & 0.10 & 0.76 & 0.70 & 0.82 & 0.84 & 0.80 & 0.87 \\
\hline$\mu_{\pi}$ & Normal & 1.70 & 0.30 & 0.89 & 0.66 & 1.11 & 1.03 & 0.82 & 1.28 \\
\hline$\mu_{y}$ & Gamma & $0.5 / 4$ & 0.10 & 0.67 & 0.52 & 0.79 & 0.63 & 0.40 & 0.98 \\
\hline$\rho_{\chi}$ & Beta & 0.50 & 0.15 & 0.93 & 0.91 & 0.96 & 0.90 & 0.87 & 0.93 \\
\hline$\rho_{z}$ & Beta & 0.50 & 0.15 & 0.94 & 0.91 & 0.98 & 0.92 & 0.87 & 0.96 \\
\hline$\sigma_{p}$ & Inv Gamma & 0.15 & 0.15 & 1.19 & 0.87 & 1.64 & 0.98 & 0.75 & 1.33 \\
\hline$\sigma_{w}$ & Inv Gamma & 0.15 & 0.15 & 1.11 & 0.89 & 1.32 & 1.27 & 0.98 & 1.58 \\
\hline$\sigma_{r}$ & Inv Gamma & 0.15 & 0.15 & 0.15 & 0.13 & 0.18 & 0.14 & 0.12 & 0.17 \\
\hline$\sigma_{z}$ & Inv Gamma & 0.15 & 0.15 & 1.01 & 0.83 & 1.18 & 0.75 & 0.69 & 0.83 \\
\hline$\sigma_{\chi}$ & Inv Gamma & 0.15 & 0.15 & 2.98 & 2.26 & 3.85 & 2.95 & 2.55 & 3.42 \\
\hline
\end{tabular}

pre-Volcker period than during the Great Moderation. In addition, there are important differences in the Calvo parameter estimates. A comparison of the estimation results from the two samples shows that the difference between wage and price stickiness parameters in the two models becomes significant when the pre-Volcker period is considered, as wage stickiness was higher and price stickiness was lower compared to the more recent period of the Great Moderation.

The third set of parameter estimates consists of the policy rule parameters $\left(\mu_{r}, \mu_{\pi}\right.$ and $\mu_{y}$ ). The estimates from the pre-Volcker period are similar to those found for the Great Moderation period, except for the inflation coefficient, which is significantly lower for the two models in the pre-Volcker period. This result is in line with previous evidence reported in the literature (Lubik and Schorfheide 2004; Canova 2009). Moreover, the estimated inflation coefficient, lower than one, associated with the CMV model implies that the Taylor principle did not hold during this period. The fourth set comprises the autoregressive and standard deviation of shocks. On the one hand, the autoregressive parameters $\left(\rho_{\chi}\right.$ and $\rho_{z}$ ) show a great deal of persistence across samples. On the other hand, the standard deviation of price, productivity and, to a lesser extent, IS shocks are much larger in the pre-Volcker than in the Great Moderation period. By 
contrast, the standard deviations of wage setting shocks and interest rate shocks are similar across samples.

\section{Welfare cost of business cycle fluctuations}

Let us start with a quick survey of recent results. Otrok (2001) and Lucas (2003) argue that the welfare cost of US business cycles is small. They calculate a welfare loss around $0.05 \%$ of consumption. Such low welfare cost is obtained in a model with perfect competition and flexible prices. Costain and Reiter (2005) calculate the welfare cost of business cycles in a model with search frictions and flexible prices, finding numbers significantly larger than Otrok and Lucas, in the range between 0.25 and $0.33 \%$ of consumption. Levin et al. (2005) estimate the welfare cost of US post-war business cycles using a model that incorporates two sources of nominal rigidities: sticky prices and sticky wages. They find a welfare cost of $2.6 \%$ of steady-state consumption, which is much higher than numbers from previous studies. As pointed out in their paper, nominal rigidities can bring cross-sectional dispersion in relative prices and wages that produce large disparities in labor assignments and, therefore, welfare losses. For example, the high wage dispersion observed with persistent wage stickiness would result in a vast differentiation of hours that would damage total utility.

As our particular contribution to the literature, we have calculated the welfare cost of US business cycles in the estimated models. The welfare cost would correspond to cyclical fluctuations during the Great Moderation, using the Bayesian estimation results reported in Table 1. Given the small macroeconomic volatility observed in that period, this exercise may bring a floor value for the socioeconomic cost of cyclical fluctuations. The welfare cost is obtained by quantifying the utility loss caused by short-run fluctuations. A three-step procedure is implemented. First, we take a second-order approximation to the instantaneous utility function (1) in order to find the influence of business cycle variabilities and price/wage dispersions. The second step consists of computing the unconditional expectation of the second-order approximation. It renders in the CMV model ${ }^{19}$ :

$$
\begin{aligned}
E\left[U^{C M V}\right]= & U^{s s}-\frac{1}{2} \sigma \operatorname{var}(c)-\frac{1}{2} \frac{1}{\sigma-1} \operatorname{var}(\chi)+\operatorname{cov}(c, \chi)-\frac{1}{2} \bar{\Psi} \gamma \operatorname{var}(n) \\
& -\frac{1}{2} \bar{\Psi} \gamma\left[\frac{\theta^{2} \eta_{p}}{(1-\alpha)^{2}\left(1-\eta_{p}\right)^{2}} \operatorname{var}\left(\triangle^{\delta} \pi^{p}\right)\right. \\
& \left.+\frac{\theta^{2} \eta_{w}^{2} \tau_{1}^{2}}{(1-\alpha)^{2}\left(1-\eta_{w}\right)^{2}} \frac{\left(1-\eta_{p}\right)}{\left(1-\eta_{w} \eta_{p}\right)} \operatorname{var}\left(\triangle^{\delta} \pi^{w}\right)\right]
\end{aligned}
$$

where $\operatorname{var}(a)$ refers to the unconditional variance of variable $a, \operatorname{cov}(a, b)$ denotes the unconditional covariance between variables $a$ and $b$, and both $\triangle^{\delta} \pi^{p}=\pi^{p}-\delta_{p} \pi_{-1}^{p}$ and $\triangle^{\delta} \pi^{w}=\pi^{w}-\delta_{w} \pi_{-1}^{w}$ are changes in price inflation and wage inflation adjusted

19 The proof is written in a technical appendix available from the authors upon request. Steady-state employment has been normalized to one, which implies unit steady-state consumption. 
using the indexation weights. ${ }^{20}$ The last line of $E\left[U^{C M V}\right]$ collects the welfare cuts caused by nominal rigidities because it would be cancelled out with both flexible prices and flexible wages, i.e. by setting $\eta_{p}=\eta_{w}=0$. Finally, the third step measures the welfare cost of cyclical fluctuations as the percentage increase in consumption required to compensate for the utility loss caused by short-run variability.

For a comparison, the unconditional expectation of the utility function in the EHL model is given by the following expression

$$
\begin{aligned}
E\left[U^{E H L}\right]= & U^{s s}-\frac{1}{2} \sigma \operatorname{var}(c)-\frac{1}{2} \frac{1}{\sigma-1} \operatorname{var}(\chi)+\operatorname{cov}(c, \chi)-\frac{1}{2} \bar{\Psi} \gamma \operatorname{var}(n) \\
& -\frac{1}{2} \bar{\Psi} \gamma\left[\frac{\theta^{2} \eta_{p}}{(1-\alpha)^{2}\left(1-\eta_{p}\right)^{2}} \operatorname{var}\left(\triangle^{\delta} \pi^{p}\right)+\frac{\theta_{f}^{2} \eta_{w}}{\left(1-\eta_{w}\right)^{2}} \operatorname{var}\left(\triangle^{\delta} \pi^{w}\right)\right] .
\end{aligned}
$$

The difference between $E\left[U^{C M V}\right]$ and $E\left[U^{E H L}\right]$ is ${ }^{21}$

$$
\begin{aligned}
& E\left[U^{C M V}\right]-E\left[U^{E H L}\right] \\
& =-\frac{1}{2} \bar{\Psi} \gamma\left(\frac{\theta^{2} \eta_{w}^{2} \tau_{1}^{2}}{(1-\alpha)^{2}\left(1-\eta_{w}\right)^{2}} \frac{\left(1-\eta_{p}\right)}{\left(1-\eta_{w} \eta_{p}\right)}-\frac{\theta_{f}^{2} \eta_{w}}{\left(1-\eta_{w}\right)^{2}}\right) \operatorname{var}\left(\triangle^{\delta} \pi^{w}\right),
\end{aligned}
$$

which may be either positive or negative. This difference captures the distinct treatment of the labor market and wage setting between the two models.

Table 9 reports the results of the welfare cost of cyclical fluctuations measured by the consumption equivalent. The baseline CMV model estimates a welfare loss of $0.60 \%$ of steady-state consumption. The version of the sticky-wage model of EHL (2000) delivers a lower welfare loss estimate equal to $0.31 \%$ of steady-state consumption. These numbers are clearly larger than Lucas and Otrok's estimates, probably because they did not allow labor dispersion in their perfect competition setup without wage rigidity. In addition, the welfare loss of business cycles in the CMV model is also larger than the number found by Costain and Reiter (2005), which suggests that search frictions are not as influential as sticky wages for employment dispersion. However, the numbers obtained here are approximately one third of the values provided by Levin et al. (2005) in a model also featuring sticky prices and sticky wages. Such difference can be due to two reasons: (i) Levin et al. (2005)'s number is obtained with post-war data that shows higher cyclical variability, and (ii) Levin et al. (2005)'s model includes real money balances in the utility function which adds welfare losses coming from monetary fluctuations.

Also shown in Table 9, the CMV model gives a higher welfare cost than the EHL model $(0.60$ vs $0.31 \%)$. The higher cost of short-run fluctuations in the CMV model

\footnotetext{
20 It should be noticed that the adjusted change of price inflation gives a measure of "price dispersion" since it is proportional to the log deviation between optimal prices and the aggregate price level, $\triangle^{\delta} \pi^{p}=$ $\frac{1-\eta_{p}}{\eta_{p}} \log \left(\frac{P^{*}}{P}\right)$. The same kind of relationship applies to nominal wages, $\triangle^{\delta} \pi^{w}=\frac{1-\eta_{w}}{\eta_{w}} \log \left(\frac{W^{*}}{W}\right)$.

21 Obviously, this difference holds only in case the models were empirically equivalent with the same estimates for the structural parameters and identical variance-covariance statistics.
} 
Table 9 Welfare cost of business cycle fluctuations (\% of steady-state consumption)

\begin{tabular}{lll}
\hline & CMV model & EHL model \\
\hline Baseline estimation & 0.60 & 0.31 \\
Imposing flexible wages $\left(\eta_{w}=0\right)$ & 0.31 & 0.16 \\
Imposing flexible prices $\left(\eta_{p}=0\right)$ & 0.28 & 0.20 \\
Imposing flexible wages and prices $\left(\eta_{w}=\eta_{p}=0\right)$ & 0.23 & 0.08 \\
Shutting down demand shocks $\left(\chi=\varepsilon^{R}=0\right)$ & 0.15 & 0.18 \\
Shutting down cost-push shocks $\left(v^{p}=v^{w}=0\right)$ & 0.48 & 0.15 \\
Shutting down demand and cost-push shocks $\left(\chi=\varepsilon^{R}=v^{p}=v^{w}=0\right)$ & 0.04 & 0.02 \\
\hline
\end{tabular}

can be explained by the greater impact of sticky wages on labor fluctuations. As indicated in the expression of $E\left[U^{C M V}\right]-E\left[U^{E H L}\right]$, wage dispersion has a stronger (negative) impact in the CMV model. Intuitively, wage rigidity generates employment dispersion that is amplified by the interaction between wage setting and price setting. For example, one firm that was not able to reset the wage in the midst of a demand contraction has higher-than-average wages, marginal costs, prices which would reduce significantly the labor demand and effective employment. In the EHL model, wage setting behavior is driven by the household-specific mrs gap, which has no direct connection on price setting and effective labor demand. A higher wage rigidity results in a deep reallocation of specific labor services supplied by different households.

The last term on the expressions for $E\left[U^{C M V}\right]$ and $E\left[U^{E H L}\right]$ shown above brings the contribution of nominal rigidities to the welfare cost of business cycles. Actually, Table 9 reports that nominal rigidities cause most welfare cost of business cycle. If either flexible prices or wages are imposed in the model the welfare loss due to cyclical fluctuations falls significantly. Thus, having flexible prices in the estimated CMV model cuts welfare cost in approximately half (from 0.6 to $0.28 \%$ ). A similar reduction is observed when having flexible wages (from 0.60 to $0.31 \%$ ). ${ }^{22}$ Therefore, price stickiness and wage stickiness have similar responsibility on the welfare loss due to cyclical fluctuations. In the EHL model, the results obtained when eliminating either price or wage stickiness are of similar relevance.

If both flexible prices and wages are assumed, the cost of business cycles is approximately $1 / 3$ of the total cost obtained with nominal rigidities. This result is found in both models. Subsequently, we can say that $2 / 3$ of the welfare cost of business cycles can be attributed to nominal frictions on price/wage settings and only $1 / 3$ is due to shocks variability. The numbers found under flexible prices/wages are much closer to Lucas' estimate than the ones obtained in the baseline version of the models. Moreover, these numbers are slightly smaller than Lucas' estimates when shutting down demand shocks and cost-push shocks, and only technology shocks would shape the business cycle. In relative terms, Table 9 shows that shutting down demand shocks reduces the cost of business cycle more than shutting down cost-push shocks (especially in the CMV model where eliminating demand shocks cut $3 / 4$ of total welfare

\footnotetext{
22 Jung and Kuester (2009) find a welfare cost of business cycles close to $0.20 \%$ of steady-state consumption in a model that combine sticky prices, search frictions and flexible wages.
} 
cost). Therefore, demand shocks are the exogenous source of variability behind the largest portion of the welfare cost of cyclical fluctuations.

\section{Conclusions}

The New-Keynesian model has been recently extended to incorporate endogenous fluctuations of unemployment due to search frictions (Trigari 2009; Walsh 2005) or, alternatively, to sticky wages (Casares 2007, 2010; Galí 2011). We borrow the labor market structure of Casares (2010) and add inertial behavior of price and wage dynamics to describe a medium-scale New-Keynesian model with unemployment explained by wage rigidity (CMV model). The CMV model is estimated with Bayesian econometric techniques and compared to an estimated version of the sticky-wage model of Erceg et al. (2000), referred here as the EHL model, to examine the empirical implications of introducing unemployment. We use quarterly US data from the "Great Moderation" period (1984-2008) and also from the pre-Volcker period (1957-1979). Results of the estimates of structural parameters are similar across models, although price stickiness is marginally lower and wage stickiness slightly higher in the CMV model compared with the EHL model. In the comparison across sample periods, we find that during the Great Moderation price rigidities have risen, while wage stickiness has fallen. In addition, we have found that the inertial component of price inflation is not statistically high in any sample period, which implies that US inflation dynamics have been more forward-looking than backward-looking. As for the sources of variability, demand-side shocks have been the main driving forces in recent US business cycles, as they explain most of the observed variability in output, employment, and the nominal interest rate.

The estimated CMV model provides a good matching of the second-moment statistics of unemployment obtained in the data (standard deviation, correlation with output and autocorrelation). Impulse-response functions show that unemployment is procyclical with demand shocks and countercyclical with supply shocks. In the variance decomposition of the unemployment rate, demand-side shocks, such as consumption preference innovations on the IS curve and monetary policy shocks, explain most unemployment variability. A comparable measure of unemployment in the EHL model is the log difference between labor under flexible prices/wages and effective labor; our results show business cycle patterns of this labor gap series rather close to those observed in unemployment from the CMV model.

We also estimated the CMV model under alternative detrending techniques, both with and without employment as an observable variable. In all cases, the estimation results are robust. For the pre-Volcker period, wage stickiness was higher and the Taylor-rule coefficient of the reaction of the nominal interest rate to inflation deviations was significantly lower than after 1984.

Finally, the welfare cost of short-run fluctuations during the Great Moderation has been estimated at $0.60 \%$ of steady-state consumption in the CMV model and $0.31 \%$ in the EHL model. These numbers are clearly higher than the estimate obtained by Lucas (2003) in a flexible-price model, but lower than the value reported by Levin et al. (2005) using a sticky-price, sticky-wage estimated model with post-war US data. Both 
nominal rigidities and demand shocks appear as the main factors behind the welfare cost of business cycles.

Open Access This article is distributed under the terms of the Creative Commons Attribution License which permits any use, distribution and reproduction in any medium, provided the original author(s) and source are credited.

\section{References}

Abel A, Bernanke B, Croushore D (2011) Macroeconomics, 7th edn. Prentice Hall

Atkenson A, Chari VV, Kehoe P (2011) Sophisticated monetary policies. Q J Econ 125:47-89

Blanchard OJ, Galí J (2007) Real wage rigidities and the New-Keynesian model. J Money Credit Banking 39:35-65

Blanchard OJ, Kahn CM (1980) The solution of linear difference models under rational expectations. Econometrica 48:1305-1311

Calvo GA (1983) Staggered pricing in a utility-maximizing framework. J Monet Econ 12:383-396

Canova F (2009) What explains the Great Moderation in the US? A structural analysis. J Eur Econ Assoc $7: 1-25$

Canova F, Ferroni F (2009) Multiple filtering devices for the estimation of cyclical DSGE models. Working paper 1135, Universitat Pompeu Fabra

Casares M (2007) Firm-specific or household-specific sticky wages in the New-Keynesian model? Int J Central Bank 3:181-240

Casares M (2010) Unemployment as excess supply of labor. J Monet Econ 57:233-243

Cho J, Cooley TF (1994) Employment and hours over the business cycle. J Econ Dyn Control 18:411-432

Christiano LJ, Eichenbaum M, Evans CL (2005) Nominal rigidities and the dynamic effects of a shock to monetary policy. J Political Econ 113:1-45

Christiano LJ, Motto R, Rostagno M (2008) Shocks, structures or monetary policies? The Euro Area and US after 2001. J Econ Dyn Control 32:2476-2506

Clarida R, Galí J, Gertler M (1999) The science of monetary policy: a New-Keynesian perspective. J Econ Lit 37:1661-1707

Cochrane J (2010) Determinacy and identification with Taylor rules. Mimeo. (Revised version of NBER Working Paper \#13409)

Cooley TF, Hansen GD (1989) The inflation tax in a real business cycle model. Am Econ Rev 79:733-748

Costain J, Reiter M (2005) Stabilization versus insurance: welfare effects of procyclical taxation under incomplete markets. Universitat Pompeu Fabra Working Paper \#890

Dixit AK, Stiglitz JE (1977) Monopolistic competition and optimum product diversity. Am Econ Rev 67:297-308

Erceg CJ, Henderson DW, Levin AT (2000) Optimal monetary policy with staggered wage and price contracts. J Monet Econ 46:281-313

Fernández-Villaverde J (2010) The econometrics of DSGE models. SERIEs 1:3-49

Galí J (1999) Technology, employment, and the business cycle: do technology shocks explain aggregate fluctuations? Am Econ Rev 89:249-271

Galí J (2011) The return of the wage Phillips curve. J Eur Econ Assoc 9(3):436-461

Galí J, Monacelli T (2005) Monetary policy and exchange rate volatility in a small open economy. Rev Econ Stud 72:707-734

Gertler M, Sala L, Trigari A (2008) An estimated monetary DSGE model with unemployment and staggered nominal wage bargaining. J Money Credit Banking 40:1713-1764

Goodfriend M, McCallum BT (2007) Banking and interest rates in monetary policy analysis: a quantitative exploration. J Monet Econ 54:1480-1507

Hansen GD (1985) Indivisible labor and the business cycle. J Monet Econ 16:309-327

Ireland P (2004) Technology shocks in the New Keynesian model. Rev Econ Stat 8:923-936

Ireland P (2007) Changes in the Federal Reserve's inflation target: causes and consequences. J Money Credit Banking 39:1851-1882

Jung P, Kuester K (2009) The (un)importance of unemployment fluctuations for welfare. Federal Reserve Bank of Philadelphia. Working paper $08-31 / \mathrm{R}$ 
Levin A, Onatski A, Williams J, Williams N (2005) Monetary policy under uncertainty in micro-founded macroeconometric models. In: Gertler M, Rogoff K (eds) NBER Macroeconomics Annual 2005. MIT Press, Cambridge pp 229-287

Lubik TA, Schorfheide F (2004) Testing for indeterminacy: an application to US monetary policy. Am Econ Rev 94:190-217

Lucas RE (2003) Macroeconomic priorities. Am Econ Rev 93:1-14

McCallum B (1983) On non-uniqueness in rational expectations models: an attempt at perspective. J Monet Econ 11:139-168

McCallum B (2004) On the relationship between determinate and MSV solutions in linear RE models. Econ Lett 84:55-60

Merz M (1995) Search in the labor market and the real business cycle. J Monet Econ 36:269-300

Moreno A (2004) Reaching inflation stability. J Money Credit Banking 36:801-825

Mortensen DT, Pissarides CA (1994) Job creation and job destruction in the theory of unemployment. Rev Econ Stud 61:397-415

Otrok C (2001) On measuring the welfare cost of business cycles. J Monet Econ 47:61-92

Phillips AW (1958) The relation between unemployment and the rate of change of money wage rates in the United Kingdom, 1861-1957. Economica 25:283-299

Sbordone AM (2002) Prices and unit labor costs: a new test of price stickiness. J Monet Econ 49:265-292

Smets F, Wouters R (2003) An estimated dynamic stochastic general equilibrium model of the Euro Area. J Eur Econ Assoc 1:1123-1175

Smets F, Wouters R (2007) Shocks and frictions in U.S. business cycles: a Bayesian DSGE approach. Am Econ Rev 97:586-606

Stock JH, Watson MW (2002) Has the business cycle changed and why? In: Gertler M, Rogoff K (eds) NBER Macroeconomics Annual 2002. MIT Press, Cambridge pp. 159-218

Taylor JB (1993) Discretion versus policy rules in practice. Carnegie-Rochester Conference Series on Public Policy 39:195-214

Trigari A (2009) Equilibrium unemployment, job flows, and inflation dynamics. J Money Credit Banking 41:1-33

Walsh CE (2005) Labor market search, sticky prices, and interest rate policies. Rev Econ Dyn 8:829-849

Woodford M (2003) Interest and prices: foundations of a theory of monetary policy. Princeton University Press, Princeton 